\title{
PHILELOGGEA
}

Philologica Canariensia 21 (2015), 151-163 eISSN: 2386-8635

DOI: 10.20420/PhilCan.2015.0038

\section{UN ESCRITO DE FRANCISCO GONZÁLEZ DÍAZ ATRIBUIDO A RAMÓN GÓMEZ DE LA SERNA}

\author{
ANTONIO HENRÍQUEZ JIMÉNEZ \\ Investigador independiente
}

\begin{abstract}
RESUMEN
Se presenta información que prueba que Francisco González Díaz es el autor de una carta atribuida a Ramón Gómez de la Serna en un periódico de 1985. En esta carta, escrita en septiembre de 1921, el hacía poco fallecido poeta Tomás Morales es alabado de manera entusiasta.
\end{abstract}

Palabras Clave: Tomás Morales, Alonso Quesada, Francisco González Díaz, Ramón Gómez de la Serna, Manuel González Sosa, Andrés Sánchez Robayna

A Letter of Francisco González Díaz Attributed to Ramón Gómez de la Serna

\section{ABSTRACT}

We present information that proves that Francisco González Díaz is the author of a letter attributed to Ramón Gómez de la Serna in a newspaper of 1985. In this letter, written in September 1921, the recently deceased poet Tomás Morales is praised enthusiastically.

KeYwords: Tomás Morales, Alonso Quesada, Francisco González Díaz, Ramón Gómez de la Serna, Manuel González Sosa, Andrés Sánchez Robayna

El 11 de septiembre de 1921, El Tribuno, periódico republicano de Las Palmas de Gran Canaria, publicaba, bajo el rótulo "En el Círculo Mercantil. Por la memoria de Tomás Morales”, "las bellas palabras pronunciadas por don Bernardino Valle Gracia en el acto con que se honró la memoria del poeta, y la carta que el señor González Díaz 
envió como cariñosa y admirable adhesión a Tomás Morales”. El escrito de González Díaz, algo más amplio y ordenado de otra manera, se publica en el Diario de la Marina de La Habana, y ve segunda luz, indicando su procedencia, en Gaceta de Tenerife el 16 de noviembre de 1921. Ambos escritos debieron de elaborarse simultáneamente. No es lo único de González Díaz que aparece en la prensa sobre la muerte de su pariente y amigo, desde su fallecimiento a mitad de agosto de 1921 hasta la primera mitad de noviembre. He llegado a contabilizar siete textos con su firma en ese período. El fin principal de este artículo es la presentación de estas dos versiones del escrito de González Díaz, sacando una de ellas de la atribución errada a un grande de nuestras letras, como lo es Ramón Gómez de la Serna, y dando un toque de atención sobre la obra de este escritor "molesto" para ciertas clases depredadoras, no solo del medio ambiente, en las cercanías del sesquicentenario de su nacimiento.

El 22 de agosto de 1921, González Díaz escribe a París a su amigo Luis Doreste Silva. El siguiente fragmento de esa carta manifiesta sintéticamente lo elaborado en los escritos de El Tribuno y del Diario de la Marina:

\section{Teror, 22 de agosto ${ }^{1}$}

Ya sabrá la tremenda noticia. iTomás Morales ha muerto! iQué pesar tan horrible! iQué desolación!

Se fue temprano, como los favoritos de los dioses, dueño de la fortuna y de la gloria, esa otra y mucho mayor fortuna, que irá creciendo sin cesar, pues yo creo firmemente que Tomás figurará para siempre entre los más grandes poetas de nuestra raza. Volviendo a leerle ahora, le encuentro perfecto y único. Él fue feliz hasta en la muerte; nosotros no nos consolaremos jamás. Se ha ocultado una estrella, nuestra estrella ...

La carta de El Tribuno, algo cambiada, se volvió a publicar muy posteriormente en el periódico Jornada de Santa Cruz de Tenerife ("Jornada Literaria”, 19 de enero de 1985), bajo el título "Una carta inédita de Ramón a Alonso Quesada. Sobre Tomás Morales", acompañada de una "Nota”, en la que el profesor Andrés Sánchez Robayna, a la vez que se alegraba de que apareciera una de las cartas de la correspondencia de Ramón Gómez de la Serna con Alonso Quesada, ${ }^{2}$ atemperaba el entusiasmo con la cautela de que el documento presentado era una "transcripción mecanográfica debida probablemente al propio Rodríguez Iglesias", achacando el tono “decididamente 
entusiasta - ditirámbico, diríamos con Manuel González Sosa- de esos juicios” a "alguna injusticia crítica anterior en la valoración de la obra de Morales" por parte de Ramón. ${ }^{3}$ La autoridad moral de Rodríguez Iglesias y el entusiasmo de González Sosa dieron por buena la atribución de la carta a Ramón Gómez de la Serna. También se publicó la carta, con la "Nota” de Sánchez Robayna, en el cuaderno de Manuel González Sosa titulado Tomás Morales. Cartapacio del Centenario. Con una carta inédita de Ramón Gómez de la Serna (1988).

Copiándola de alguna de estas dos fuentes, ${ }^{4}$ sin indicarlo, la carta ha visto también la luz en el libro Memorias de Colombine la primera periodista, de Federico Utrera, ${ }^{5}$ con una introducción ${ }^{6}$ y el retrato moral de Alonso Quesada que hace Ramón, seguido del fragmento "Alegría" del "Canto Sexto" del Poema truncado de Madrid, de Alonso Quesada. El citado retrato de Alonso Quesada dice:

Este poeta canario sin la obsedancia isleña y torva de algunos otros poetas de su tierra, nos dedicó los versos de su alta comprensión y en cuya inspiración conversacional revela un alma blanda, opuesta a esas almas madrepóricas7 y desconfiadas con que nos suelen llegar los poetas isleños. (Gómez de la Serna, 1986 [1926], 421-422; Gómez de la Serna, 1941, 155)

Pero Utrera y sus informantes parecen tener gran interés en presentar estas palabras de Ramón, troceadas y en boca de Carmen de Burgos, como referidas a Tomás Morales. ${ }^{8}$ Parece fuera de lugar achacar a deducidas rencillas amorosas ocurridas hacía más de diez años unas supuestas desavenencias entre los dos escritores.

Sabiendo ahora que el escrito “ditirámbico" pertenece a Francisco González Díaz, y que no hay motivo para suponer un arrepentimiento de Ramón de ninguna anterior mala acción contra Morales, sería interesante (además de dejarse, a estas alturas, de disminuir la calidad humana de Morales) poner nombres a esos poetas canarios obsedantes ${ }^{9}$ y torvos, de "almas madrepóricas y desconfiadas" conocidos por Ramón, ya que todas las referencias en la prensa y revistas peninsulares sobre Tomás Morales nos lo presentan como un ser encantador y muy social, además de como un gran poeta. ${ }^{10}$ Fueron muchos los escritores, y no escritores, canarios que pasaron por Pombo, como se puede leer en los dos libros citados de Ramón. ${ }^{11}$

En cuestiones de literatura, como en otras, es fácil que el entusiasmo nos haga ir por caminos no rectos. Este fue el caso al encontrar mecanografiada la carta de 
González Díaz (que no solía escribir a máquina) en el archivo de Rodríguez Iglesias, atribuida a Ramón y dirigida a Rafael Romero. Esto último tiene su explicación, pues Alonso Quesada era uno de los organizadores del homenaje necrológico al recién fallecido amigo. Participó en la velada recitando versos de Morales y leyendo la carta de González Díaz, dirigida, sin duda, a él. En el programa publicado en la prensa, ya aparecía este pormenor: "Palabras iniciales, por don Bernardino Valle y Gracia. / . . . / A Rubén Darío en su última peregrinación, Balada del niño arquero y Tiendecitas de turcos (Versos de Tomás Morales, dichos por don Rafael Romero). / . . . / Oda a las glorias de don Juan de Austria, Himno al Volcán, Britania Máxima (Versos de Tomás Morales, leídos por don Juan Díaz Quevedo). / . . / De los Poemas de la Gloria, Canto Romántico y Serenata; de los Poemas del Mar, El mar es como un viejo . . . (Versos de Tomás Morales, recitados por don S. Suárez León). / . . . / Una carta de don Francisco González Díaz" (El Liberal, 7 de septiembre de 1921). Los espacios entre corchetes son las actuaciones musicales del septimino que dirigía Agustín Hernández.

Diario de Las Palmas, después del homenaje (10 de septiembre de 1921), precisa lo ocurrido: alaba las palabras de Bernardino Valle, y sigue:

En las tres partes que comprendía la velada homenaje, recitaron poesías de Tomás Morales don Rafael Romero Quesada, don Sebastián Suárez León y don Juan Díaz Quevedo.

El señor Romero Quesada leyó una hermosa y sentida carta del señor González Díaz que, por indisposición, no pudo asistir personalmente; y últimamente nuestro compañero Alfredo S. Pérez dio lectura a unas cuartillas escritas con todo el amor de su alma por Luis Doreste, nuestro cronista en París, que remitió para Diario de Las Palmas y que nuestro Director cedió para que antes se conocieran en la velada de anoche. En otro lugar de ese número honramos nuestras columnas, publicándolas.

La participación en la velada de González Díaz ya había sido avanzada por $E l$ Tribuno (25 de agosto de 1921): "En memoria de Tomás Morales": "El programa aún no está confeccionado; pero sabemos tomarán parte valiosos elementos, entre los que figuran la lectura de poesías de Tomás Morales por los que fueron sus buenos amigos Rafael Romero y Saulo Torón; González Díaz, Bernardino Valle”. Diario de Las Palmas (27 de agosto de 1921) decía: "El acto terminará con unas sentidas cuartillas que ha 
enviado, desde Teror, el ilustre escritor don Francisco González Díaz”. La Provincia (11 de septiembre de 1921), al reseñar el acto, cita la intervención de González Díaz del siguiente modo: "Don Francisco González Díaz nos hizo admirar en sentida carta (que fue enormemente aplaudida) las galanuras de su estilo”. Es más, el 15 de septiembre publica una "Carta abierta" de J. Rodríguez Quintana, en la que alaba las palabras de Valle y el escrito de González Díaz de la siguiente manera:

He leído hoy en El Tribuno las sencillamente magistrales palabras del uno y la soberanamente bella carta del otro... . Se ve que González Díaz escribió su carta fraternal vertiendo copioso llanto. El literato ilustre, el periodista insigne, de vastísima cultura; el orador genial, grandilocuente, no se resigna a la pérdida irreparable del vate excelso, del amigo entrañable. Yo le veo suspender su labor, y mirar ansioso al firmamento, sondeando, escudriñando, inquiriendo el infinito, pretendiendo ver solidificado el éter, buscando el celeste espíritu del poeta eminente para hacerle la ofrenda amorosa de una lágrima.

Puesto en conocimiento de Manuel González Sosa el hallazgo del artículo de $E l$ Tribuno, obró con la mesura que le caracterizaba aceptando de entrada el hecho, y haciéndose sus preguntas. En primer lugar, se resistía a admitir que un hombre de la categoría moral del director del grupo teatral Los Doce hubiera caído en tal despiste. A la par, se preguntaba la causa de aquella primera alusión a un telegrama y a una carta, que parecía casar mejor con alguien que escribiera desde lejos (la noticia del periódico de que González Díaz se encontraba en Teror deshacía este argumento de la lejanía del remitente); o recordaba un texto de Ramón cuando visitó, de paso hacia América, Las Palmas, en el que hablaba del "criollismo" ( $\sin$ emplear el término) de nuestro ambiente; ${ }^{12}$ o la impresión de ajenidad del contenido de la carta, que no parece escrita por alguien del terruño (a lo que el que esto escribe respondía con ejemplos casi iguales del apóstol del árbol cuando criticaba acciones de sus coterráneos); o el dato de no haber encontrado ninguna nota en contra de la autoría de la carta de González Díaz en los periódicos locales de la época.

Manuel González Sosa comunicó al profesor Andrés Sánchez Robayna la evidencia del posible "desliz", casi vislumbrado en la citada nota publicada en Jornada Literaria de 1985. El lector de la obra crítica de González Sosa conoce su labor esclarecedora en varios casos de errores en que han caído excelentes especialistas en 
materias literarias. Comentaba con el que esto escribe cómo el descubrimiento de un dato posterior tira por tierra algo que se tenía como ya asentado; o de casos de plagios, como el del Soneto al Teide del Vizconde de Buen Paso, que resultó ser una traducción no muy feliz de un texto portugués, y que él desentrañó con cierta amargura, por lo que significaba de caída de un mito; o de famosas manipulaciones interesadas, o de la incomprensible atribución de autoría en alguien tan alerta como Enrique Díez-Canedo; de la asignación, entre los canarios, del poema "La Pulga", de Lope de Vega, al guiense Rafael Bento y Travieso; o de la aviesa respuesta de un tenido como especialista en un autor canario a un investigador bisoño que le pide algunos versos inéditos del tal autor y le proporciona versos de otro, con el fin evidente de desacreditarlo cuando los publicara.

Pero González Sosa se resistía a pensar que un Rodríguez Iglesias pudiera haber tenido el descuido de trocar la autoría de una carta, y llegaba a pensar que la pasaría a máquina mucho tiempo después de aquel recuerdo al poeta fallecido. Tampoco se quedaba conforme al argumentarle que posiblemente el periódico transcribe dos lecturas de Rafael Romero: primera, el telegrama enviado por Ramón (y posiblemente otros telegramas de amigos literatos de allende el mar); y segunda, la carta de González Díaz. Pero nada de eso se ha encontrado en las noticias allegadas hasta ahora. ${ }^{13}$

Presento a continuación la carta de González Díaz a El Tribuno, seguida del escrito del mismo autor publicado en Gaceta de Tenerife, que lo toma del Diario de la Marina de La Habana.

\section{CARTA DE GoNZÁlEz DíAZ PUBLICADA EN EL TRIBUNO}

\section{Queridos amigos: ${ }^{14}$}

El desastre de la muerte de Tomás es algo horrendo, inexplicable. Gimo aún bajo su agobio, como bajo la presión de una torturadora pesadilla. Era un poeta rey. Yo, admirándole mucho pero equivocándome, juzgué su obra una iniciación triunfal, y le pedía y esperaba más cosas, cosas mayores.

He vuelto a leer con recogimiento emocionado Las Rosas de Hércules; icuán cierto es que necesitamos cierta distancia, cierta perspectiva, para apreciar bien las grandes magnitudes! Ahora, creo, firmememente, que la obra de Tomás tiene un valor definitivo, absoluto y eterno. Viviendo largo, pudo hacer más, pero no pudo hacer 
mejor. iQué potencia enorme! iQué rica armonía! iQué manera de decir tan portentosa! Reunía nuestro bardo todas las características de los creadores geniales. Forjose una lengua nueva, dentro de la lengua hispana. Se creó su expresión propia, perfectísima. Asombrosos, realmente asombrosos el número, la pompa y la plasticidad de sus formas expresivas, el vivero de su vocabulario. ¿Dónde descubrió la mina sin fin? Vegetación fantástica detenida en su crecimiento pero indestructible y única. Gruta milagrosa en que las estalactitas y estalagmitas dibujan sublimes caprichos arquitecturales, decorativos. Dio al elemento formal tanta sutileza y agudeza, tanta fineza de penetración y exteriorización, que sus estrofas se fijan, se yerguen como cristalizaciones mágicas. El mismo Rubén Darío, con quien hemos de compararle, tuvo tiempo para realizar una labor más amplia y compleja, pero no le igualó en esta suma exquisitez artística. No, no le igualó. Rubén cae a menudo, aunque se levanta bruscamente. Tomás no cae nunca.

$\mathrm{Su}$ verbo, el verbo de Tomás, es omnipotente. Grita iExcelsior! y escala las supremas alturas. Le asisten los poderes de las artes todas. Pintor, su paleta es el iris celeste desleído; escultor, saca de ingentes bloques pétreos estatuas serenísimas; músico, roba a la naturaleza la clave de sus sínfonías vastas y perpetuas. A veces se oye una música profunda y lejana, como de selva tañida por el viento, como de mar batallador, como de mundo que se despierta o se duerme ... Y su verbo está fundido en bronce, esculpido en mármol, labrado en oro, cincelado en otros metales misteriosos, preciosos, con destreza, parsimonia y delectación cellinescas. ${ }^{15}$

Alomar supo definirlo: bajo una severa armonía clásica, una abundancia tórrida. De los parnasianos la serenidad olímpica, pero en extraño ayuntamiento con no sé qué criollismo estético, con alucinaciones pátmicas $^{16}$ de un gran vidente asomado al Infinito. Heredia, sí, Leconte de Lisle, sí, pero en mayor temperatura. El amor de Tomás Morales al oceano es inaudito e ilógico: el amor de la llama al agua ...

Era un poeta rey. No concebía en pequeño. Sus asuntos revestían la grandeza de cuadros épicos desmesurados, de reconstrucciones ciclópeas o de adivinaciones proféticas bajo las alas de águilas inspiradoras. Su inspiración se perdía en inmensidades. Viviendo largo tiempo pudo hacer más, pero no pudo hacer mejor. Britania Máxima, la oda a Don Juan de Austria, La tarde en la selva, Alegoría de Otoño, la oda al Atlántico, La Balada del niño arquero, el canto elegíaco a Rubén Darío, bastan y sobran para consagrarle multimillonario del pensamiento. Tesoro breve, ${ }^{17}$ pero inestimable. iLa riqueza suntuaria de un nabab cabe en un cofrecillo! 
Claro que esto no lo comprende nuestra turba filistea; será preciso que se lo digan y se lo prueben los de fuera, pero se lo dirán y se lo probarán. Tomás Morales quedará consagrado uno de los más grandes poetas de la estirpe latina. Su memoria nada ${ }^{18}$ tiene que temer del Tiempo.

Vosotros, intelectuales, debéis conservarla y alimentarla como fuego sagrado en la pira encendida perennemente para honrar los manes de un Dios.

Abrazos cordiales en este gran dolor, que debe ser de todos.

Francisco González Díaz.

\section{CARTA DE GONZÁlez DíaZ PUbliCADA EN GACETA DE TENERIFE, QUE LA TOMA DEL DIARIO DE LA MARINA DE LA HABANA}

"Los grandes poetas canarios. Tomás Morales"19

Estamos bajo el peso de una gran desgracia. Ha muerto Tomás Morales después de una gran agonía: agonía de un astro que iba a perderse lentamente en el infinito, de donde saliera. Y nosotros nos damos cuenta de lo que perdemos. Con Morales habíamos incorporado un luminar a la constelación prestigiosa que brilla bajo los rayos de Apolo. Una ola negra se lo ha llevado; no la pudo detener la ciencia, desesperada, ni la amistad, ni el amor, ni la admiración de un pueblo entero. Se ocultó el astro. Queda su huella en el horizonte, creciendo, creciendo, creciendo como la ola del naufragio, para salvar y tornar imperecedero lo que la ola destruyó. El Destino se ha vuelto loco, decíamos; no puede ser, no puede ser. Y fue ...

Tomás Morales desaparece entre los oros solares de su triunfo, en plena mañana de su vida, pero deja una luminosísima estela que afirmará su memoria. Su memoria nada tiene que temer del tiempo.

Era un poeta-rey. Yo, admirándole mucho pero equivocándome, juzgué su obra una iniciación triunfal, y le pedía más cosas, cosas mayores. He vuelto a leer con recogimiento emocionado Las Rosas de Hércules. iCuán cierto es que necesitamos cierta distancia, cierta perspectiva para apreciar bien las magnitudes! Hoy creo, firmemente, que la obra de Tomás tiene un valor definitivo, absoluto y eterno.

Viviendo largo, pudo hacer más, pero no pudo hacer mejor. iQué potencia enorme! iQué rica armonía! iQué manera de decir tan portentosa! Tenía nuestro bardo 
todas las características de los creadores geniales. Forjose una lengua dentro de la lengua hispana; se forjó su expresión propia, perfectísima. Asombrosos, realmente asombrosos el número, pompa y plasticidad de sus formas expresivas, el vivero de su vocabulario. ¿Dónde descubrió la mina inagotable? Vegetación fantástica detenida en su pululamiento, pero indestructible y única. Gruta milagrosa en que las estalactitas y estalagmitas dibujan sublimes caprichos arquitectónicos, decorativos.

$\mathrm{Su}$ verbo era omnipotente. Le asistían los poderes de las artes todas. Pintor, su paleta era el iris celeste desleído; escultor, sacaba de ingentes bloques pétreos estatuas serenísimas; músico, robó a la naturaleza la clave de sus sínfonías vastas y perpetuas. $\mathrm{Su}$ verbo está fundido en bronce, esculpido en mármol, labrado en oro, cincelado en otros metales misteriosos, preciosos, con destreza, parsimonia y delectación cellinescas. A veces se oye una música profunda y lejana, como de selva tañida por el viento, como de mar batallador, como de mundo que se despierta o se duerme . . . La cantan sus solemnes estrofas.

Alomar supo definirlo: bajo una severa armonía clásica, una abundancia tórrida. De los parnasianos la serenidad olímpica, pero en extraño ayuntamiento, con no sé qué criollismo estético, con las alucinaciones pátmicas de un gran vidente asomado al Cosmos. Heredia, sí; Leconte de Lisle, sí, pero a mayor temperatura. El amor de Tomás Morales al océano es inaudito e ilógico: el amor de la llama al agua. Su inspiración ardiente como un incendio necesitaba refrescarse.

Era poeta erudito, auxiliado de una vasta cultura. Nos sorprende, ya lo dije, el número de palabras bien halladas y bien sonantes que incorporó al lenguaje rítmico, engrandeciéndolo. No le comprenderán aquellos porta liras que todavía conservan "el traje corto", las combinaciones elementales de la métrica. Hay en su obra un nuevo mundo lexicográfico, henchido e hirviente, que se organizaba bajo la ley de una soberana inteligencia. Iba recamando de perlas la veste magna de la Poesía, puesta "de largo” por Rubén ... Todos los elementos artísticos se le entregaban y le obedecían.

Tiraba a lo épico. El espacio, el mar, las odiseas, los periplos, las majestades y dominaciones de la naturaleza, las grandiosas perspectivas de la historia animada, el pasado vivo, no muerto, le sugestionaban fuertemente. Se movía con holgura en los escenarios poemáticos. La oda a D. Juan de Austria, la "Oda al Atlántico" y "Britania Máxima”, lo prueban. Lo prueba también su canto elegíaco al tránsito de Rubén Darío, 
que es, sin duda, una visión épica de la muerte y de la eterna nocturnidad, desfile de sombras que evocan las viejas epopeyas. Pasan las caravanas espectrales. Todo el panorama de los Campos Elíseos está allí. Aun en los asuntos genéricamente líricos, Morales despliega sus magníficas fanfarrias. Esto no arguye que no sepa tratar delicadamente los motivos del reino interior; ejemplo, su elogio a Fernando Fortún, largo sollozo de la amistad enlutada.

Tenía una segunda vista amplificadora que le permitía desdoblar y magnificar las realidades, proyectarlas sobre planos enormes: un orientalismo profundo de lo complicado y lo suntuoso. Jugaba con las frases exquisitas como con gemas, en un delirio sultanesco. Se nutría de medulas leoninas. Y, en medio de aquel banquete olímpico, su pulmón de titán soplaba un gran viento germinativo. Acumulaba dificultades técnicas por el gusto de superarlas.

Viviendo largo pudo hacer más, pero no pudo hacer mejor. Breve su tesoro, pero inestimable. iLa riqueza suntuaria de un nabab cabe en un cofrecillo!

Todo esto nos pertenece en herencia de hermanos a quienes amó entrañablemente; pero, ilo hemos perdido a él!

Francisco González Díaz.

\section{NOTAS}

1 González Díaz le dice a Doreste que le escribe aprovechando que otro amigo va a París.

2 Encontrada entre los papeles de don José Rodríguez Iglesias, alma del grupo teatral Los Doce, con motivo de la preparación de la exposición sobre Tomás Morales organizada por Manuel González Sosa. Se trata del archivo de Los Doce, en manos de la escritora María Dolores de la Fe Bonilla, donde se hallaba una versión manuscrita de La cena de Bethania, de Tomás Morales, que fue entregada por Manuel González Sosa al archivo de Tomás Morales, sito entonces en la Biblioteca Insular de Las Palmas de Gran Canaria.

3 No he llegado a conocer hasta ahora ningún indicio de tal "injusticia crítica"; sí de las cicaterías de algunos críticos y los denuestos de Francisco González Díaz contra los poetas modernistas, hasta que apareció el libro Poemas de la gloria, del amor y del mar de Morales, en 1908, donde tuvo que plegar velas y olvidarse de todos los escritos en que abominaba de los poetas jóvenes y de su manera de hacer versos, y no tiene más remedio que decir que Morales es "un modernista que justifica al Modernismo; un poeta ponderado y armonioso, sin dejarse ir a las audacias extremas que han concluido por ponernos en guardia y en recelo contra los que, amparados de esa insignia sectaria, solo saben construir logomaquias indescifrables, solo saben trazar signos cabalísticos en la movediza arena”. Véase Antonio Henríquez Jiménez, Poemas de la gloria, del amor y del mar de Tomás Morales. Materiales sobre la recepción.

4 Se transcribe tal cual, sin leer las dos palabras ilegibles que se hallan en las dos citadas publicaciones. 
5 Muchísimos de los datos y fechas ofrecidos en esta especie de biografía novelada de Colombine no están contrastados y llevan a confusión a los lectores y a investigadores poco avisados.

6 RAMÓN: "ME EQUIVOQUÉ CON TOMÁS EL POETA REY". Ramón Gómez de la Serna, que había vertido despectivos comentarios hacia Tomás Morales, muestra un sincero arrepentimiento al conocer la muerte del poeta, lo que le traslada al común amigo Alonso Quesada.

7 En la publicación argentina faltan unas palabras. Allí aparece de la siguiente manera: "comprensión y opuestas a esas almas madrepóricas". Madrepórico vendría a ser "de forma arborescente y que forma escollos", algo así como "callado porque desconfía". En la Enciclopedia Universal Ilustrada (Espasa), se dice de "madrepórico": "Aspecto agujereado de ciertas concreciones y tumores óseos". ¿Querría decir Ramón "no llanos, no sencillos, no claros, sino llenos de recovecos"?

8 Dice: “un poeta canario sin la observancia [sic] isleña y torva de algunos otros poetas de su tierra, censura que todos interpretaron como dirigida a Tomás Morales. Me dicen que a Ramón le han gustado mucho los versos 'de su alta comprensión' que Rafael le ha dedicado, ' $\mathrm{y}$ en cuya inspiración conversacional revela un alma blanda, opuesta a esas almas madrepóricas y desconfiadas con que nos suelen llegar los poetas isleños'. La nueva invectiva sobre Tomás sobraba, pero son las cosas de Ramón que sigue crispado" (Utrera, 1998, 133).

9 Obsedante vendría a ser como "que asedia". El vocablo aparece en el diccionario portugués con el significado de "insistente para obtener algo", "que importuna".

10 Consúltense, al respecto, dos obras donde se recoge parte de lo que se ha opinado sobre la personalidad del poeta de Moya: Tomás Morales. Suma crítica, editado por Manuel González Sosa, y Escritos y noticias sobre Tomás Morales (1922-1972), con prólogo de Andrés Sánchez Robayna, preparado por quien firma este artículo.

11 Se ha escrito mucho sobre los visitantes canarios. Véase, por ejemplo, lo que de José Rial publica Francisco Rodríguez Batllori en su Glosario de un lector.

12 "La isla hidalga" (Luz, Madrid, 16 de junio de 1933), "reproducida por las mismas fechas en Hoy, de Las Palmas", como dice el mismo González Sosa cuando transcribió la crónica de Ramón en su Cartel (Diario de Las Palmas, 3 de noviembre de 1983). El término "criollismo" sí había sido empleado ya por González Díaz en un escrito de 1913, titulado "Hace frío", en el que se puede leer: "Porque esa tan decantada eterna primavera para nada bueno nos sirve. Tiene la culpa de nuestro enervamiento, de nuestro criollismo pesado y soso, de nuestra característica y funesta inhibición”.

13 Sobre la errada atribución de autoría de un poema de Juan Ramón Jiménez a José de Ciria y Escalante por el avisadísimo Enrique Díez-Canedo, elaboró González Sosa un artículo ("Las lecciones de un desliz", Diario de Las Palmas, 22 de septiembre de 1983, en la sección "Prontuario" de "Cartel de las letras y las artes", bajo el pseudónimo de Cifar). Al tema de las atribuciones equivocadas aludió en otro artículo titulado "Sobre un soneto 'endosado' a Bento. Aviso a navegantes", La Provincia/Diario de Las Palmas, 30 de septiembre de 2004, 42, que incluyó, ampliado, en "Sobre algunos sonetos" en Estudios Canarios. Anuario del Instituto de Estudios Canarios $(39,1994)$.

14 La carta publicada en Jornada Literaria, 177 (Jornada, Santa Cruz de Tenerife, 19 de enero de 1985) y en Tomás Morales. Cartapacio del Centenario (1988, 39-41) comienza: "Sr. Don Rafael Romero. / Querido amigo: / Recibí su telegrama, y su carta poco después”; y acaba: 
"nada tiene que temer del Tiempo". La carta mecanografiada del archivo de José Rodríguez Iglesias comienza y termina de igual modo. La de El Tribuno de 1921 no hace referencia ni al telegrama ni a la carta; y acaba con dos frases más.

15 En El Tribuno: "callinescas".

16 Esta palabra la dan como ilegible González Sosa, el periódico de Tenerife y Utrera.

17 También este adjetivo se da como ilegible en González Sosa, el periódico de Tenerife y Utrera.

18 En El Tribuno: "nadie", que parece no tener sentido. Las demás publicaciones: "nada".

19 Gaceta de Tenerife, 16 de noviembre de 1921, p. 1, tomado del Diario de la Marina, de La Habana.

\section{REFERENCIAS BIBLIOGRÁFICAS}

GÓMEZ DE LA SERNA, R. 1986 [1926]. La sagrada cripta de Pombo (tomo II', aunque independiente del $I^{o}$, pudiendo leerse el $I I^{o}$ sin contar con el $\left.I^{o}\right)$. Madrid: Trieste.

. 1941. Pombo. Biografía del célebre café y de otros cafés famosos. Buenos Aires:

Editorial Juventud Argentina.

GONZÁLEZ SOSA, M. 1988. Tomás Morales. Cartapacio del Centenario. Con una carta inédita de Ramón Gómez de la Serna. La Laguna: Instituto de Estudios Canarios.

(ed.). 1992. Tomás Morales. Suma crítica. La Laguna: Instituto de Estudios Canarios.

HENRÍQUEZ JIMÉNEZ, A. 2011a. Escritos y noticias sobre Tomás Morales (1922-1972). Prólogo de Sánchez Robayna, A. La Laguna. Instituto de Estudios Canarios.

. 2011b. Poemas de la gloria, del amor y del mar de Tomás Morales. Materiales sobre la recepción. Las Palmas de Gran Canaria: Anroart.

RODRÍGUEZ BATLLORI, F. 1977. Glosario de un lector. Madrid: Fragua.

UTRERA, F. 1998. Memorias de Colombine la primera periodista Madrid: Hijos de Muley-Rubio.

\section{PRENSA}

Diario de Las Palmas. Las Palmas de Gran Canaria, 25 de agosto de 1921, 27 de agosto de 1921, 10 de septiembre de 1921, 22 de septiembre de 1983, 3 de noviembre de 1983.

El Liberal. Las Palmas de Gran Canaria, 7 de septiembre de 1921. 
El Tribuno. Las Palmas de Gran Canaria, 11 de septiembre de 1921; 25 de agosto de 1921.

Gaceta de Tenerife. Santa Cruz de Tenerife, 16 de noviembre de 1921.

Jornada. Santa Cruz de Tenerife, “Jornada Literaria”, nº 17, 19 de enero de 1985.

La Provincia. Las Palmas de Gran Canaria, 11 de septiembre de 1921, 15 de septiembre de 1921.

La Provincia/Diario de Las Palmas. 30 de noviembre de 2004.

Luz. Madrid, 16 de junio de 1933.

Artículo recibido: 7 de octubre de 2014

Versión revisada aceptada: 21 de septiembre de 2015 